\title{
Intoxicación masiva con monóxido de carbono: puesta al día a partir de un caso
}

\author{
Massive poisoning with carbon monoxide: an update from a case
}

\author{
Dr. Mariano Díaza , Dr. Gabriel Crapanzano ${ }^{a}$, Dra. Silvia Cabrerizo ${ }^{a}$, \\ Dra. Cristina Aichele ${ }^{a}$ Dra. Alejandra Deurtiaga ${ }^{b}$ y Dra. Yamila Vallejos ${ }^{b}$
}

\section{RESUMEN}

El monóxido de carbono es conocido como "el asesino silencioso" por tratarse de un gas incoloro e inodoro. De acuerdo con estas características, su toxicidad pasa desapercibida, lo cual dificulta arribar al diagnóstico. En la mayoría de los casos, las épocas frías y la intoxicación grupal hacen sospechar su presencia, debido a que se utilizan formas inapropiadas de calefacción tanto en el ámbito domiciliario como público.

Nuestro objetivo es dar a conocer una intoxicación masiva con monóxido de carbono en un salón de fiestas infantiles en el que se utilizó una fuente de combustión instalada, no con el fin de calefaccionar, sino como abastecimiento de luz (grupo electrógeno). Se recalca que también puede ocurrir en cualquier época del año.

Palabras clave: monóxido de carbono, grupo electrógeno, intoxicación, niño.

\section{ABSTRACT}

Carbon monoxide is known as the "silent murderer" because it is a colorless and odorless gas. According to these characteristics, toxicity goes unnoticed which makes the diagnosis difficult. In most cases, the cold periods and group poisoning make suspect its presence because inappropriate heat both in home or public environments.

Our goal is to inform about a mass carbon monoxide poisoning in a children's parties room using a combustion source installed, not for the purpose of heating, but as a supply of light (generator), emphasizing that it can occur in any time of the year.

a. Centro Nacional de Intoxicaciones Hospital Nacional Profesor Alejandro Posadas, El Palomar, Buenos Aires.

b. Hospital Mariano y Luciano de la Vega, Moreno, Buenos Aires.

Correspondencia:

Dr. Mariano Díaz, marianotox@yahoo. com.ar

Financiamiento:

Ninguno.

Conflicto de intereses: Ninguno que declarar.

Recibido: 22-8-2016 Aceptado: 13-9-2016
$\mathrm{CO}$, y se estima que ocurren 40000 casos clínicos, de los que la mayoría son prevenibles y evitables. Para estimar el número de casos anuales en la cifra de 40000, se ha considerado también que muchos pacientes no consultan en el sistema de salud, por lo que existe un marcado subdiagnóstico producto de la inespecificidad de la sintomatología, la baja sospecha clínica y el subregistro de los diagnósticos. ${ }^{1}$ Gran parte de los casos están relacionados con el mal uso de braseros o el deficiente funcionamiento de artefactos de gas, ubicados en ambientes no adecuados o mal ventilados, aunque existen otras fuentes de combustión, instaladas no con el fin de calefaccionar, sino como abastecimiento de luz.

Según el Sistema Nacional de Vigilancia de la Salud (SNVS), durante el año 2015, se registraron un total de 1681 casos de intoxicaciones por CO en todo el país y un acumulado de 11996 casos en el período 2011-2015. La tasa promedio de notificaciones de intoxicaciones por CO para todo el país en el período 2011-2015 es de 8 cada 100000 habitantes. ${ }^{1}$ Por tratarse, la mayoría de las veces, de una intoxicación grupal, requiere atención inmediata y dedicada, lo cual no es una tarea fácil, debido a la gran demanda de las patologías respiratorias de la época. Las características silenciosas del gas, la intoxicación grupal que produce, el desconocimiento de su presencia y la falta de prevención demoran el diagnóstico, como así también el tratamiento adecuado.

Presentamos una intoxicación masiva con $\mathrm{CO}$ en un salón de fiestas infantiles, en la que por la sospecha de su presencia y la actuación oportuna, se evitó un desenlace desafortunado. 


\section{CASO CLÍNICO}

Se recibieron consultas telefónicas al Centro Nacional de Intoxicaciones desde dos centros de salud del conurbano bonaerense en forma simultánea por un grupo de 48 pacientes ( 27 niños y 21 adultos) con diagnóstico presuntivo de intoxicación masiva con CO (Tabla 1). Tras una hora de haber ingresado a un salón de fiestas infantiles, algunos niños y adultos comenzaron a presentar náuseas, vómitos y cefalea. Fueron trasladados a los centros de salud, donde surgió el antecedente del uso de un grupo electrógeno durante dos horas por un corte de energía eléctrica. Se les brindó inmediata y oportuna asistencia: oxigenoterapia normobárica y dosaje de carboxihemoglobina $(\mathrm{COHb})$ (Tabla 1$)$.

TABLA 1. Intoxicación masiva por monóxido de carbono según cuadro clínico, edad y dosaje de carboxihemoglobina. N: 48

\begin{tabular}{|c|c|c|c|}
\hline Número de caso & Edad (años) & Cuadro clínico & Dosaje de carboxihemoglobina (\%) \\
\hline 1. & 30 & Náuseas, vómitos, mareos & 4,4 \\
\hline 2. & 4 & Asintomático & 2,3 \\
\hline 3. & 11 & Asintomático & 4,7 \\
\hline 4. & 5 & Asintomático & 2,7 \\
\hline 5. & 4 & Asintomático & 3,5 \\
\hline 6. & 36 & Asintomático & 5,8 \\
\hline 7. & 36 & Asintomático & 10,5 \\
\hline 8. & 28 & Asintomático & 2,4 \\
\hline 9. & 38 & Asintomático & 5,8 \\
\hline 10. & 27 & Asintomático & 5,2 \\
\hline 11. & 26 & Cefalea & 8,3 \\
\hline 12. & 35 & Asintomático & 7,8 \\
\hline 13. & 33 & Asintomático & 5,2 \\
\hline 14. & 25 & Cefalea & 4,5 \\
\hline 15. & 25 & Asintomático & 7,5 \\
\hline 16. & 46 & Asintomático & 9,4 \\
\hline 17. & 49 & Asintomático & 7,6 \\
\hline 18. & 39 & Náuseas & 7,7 \\
\hline 19. & 44 & Asintomático & 10 \\
\hline 20. & 45 & Cefalea & 11,3 \\
\hline 21. & 35 & Cefalea & 11,8 \\
\hline 22. & 35 & Asintomático & 12,5 \\
\hline 23. & 35 & Asintomático & 11,8 \\
\hline 24. & 22 & Asintomático & 7,3 \\
\hline 25. & 81 & Asintomático & 7,7 \\
\hline 26. & 5 & Asintomático & 4,3 \\
\hline 27. & 4 & Asintomático & 7,2 \\
\hline 28. & 3 & Cefalea, vómitos & 3,4 \\
\hline 29. & 9 & Asintomático & 9,2 \\
\hline 30. & 8 & Cefalea & 5,5 \\
\hline 31. & 3 & Cefalea, náuseas & 2,1 \\
\hline 32. & 2 & Asintomático & 13,1 \\
\hline 33. & 6 & Vómitos & 17,2 \\
\hline 34. & 8 & Asintomático & 7,8 \\
\hline 35. & 6 & Cefalea & 13,2 \\
\hline 36. & 11 & Mareos & 14,9 \\
\hline 37. & 5 & Cefalea, mareos & 3,9 \\
\hline 38. & 12 & Asintomático & 15,9 \\
\hline 39. & 5 & Asintomático & 5,3 \\
\hline 40. & 4 & Asintomático & 6,3 \\
\hline 41. & 4 & Asintomático & MI \\
\hline 42. & 5 & Asintomático & 10,3 \\
\hline 43. & 4 & Asintomático & 1,4 \\
\hline 44. & 2 & Asintomático & 2,6 \\
\hline 45. & 5 & Asintomático & 14,1 \\
\hline 46. & 2 & Asintomático & 5,6 \\
\hline 47. & 4 & Dolor abdominal & 6,1 \\
\hline 48. & 6 & Cefalea, náuseas, vómitos & 8,1 \\
\hline
\end{tabular}

MI: muestra insuficiente.

Valor de referencia de carboxihemoglobina $(\mathrm{COHb}): 0,5 \%-1,5 \%$. 
Ningún paciente cumplió criterios para oxígeno hiperbárico (hyperbaric oxygen; HBO, por sus siglas en inglés), y todos presentaron buena evolución clínica.

\section{DISCUSIÓN}

Si bien concurrir a un salón de fiestas infantiles supone un espacio para el festejo o celebración de un evento, existen situaciones desafortunadas, aunque prevenibles, que pueden sorprendernos. Como en esta oportunidad, en muchos casos, los intoxicados son detectados por haber más de un miembro de la familia afectado. ${ }^{2}$ Recurrimos, muchas veces, a distintas fuentes de calefacción ambiental, que, por su deficiente funcionamiento, por desconocimiento o falta de recursos, nos exponen a un grave peligro. En los últimos años, debido a los sucesivos y constantes cortes de luz, ha aparecido otra fuente de intoxicación domiciliaria con $\mathrm{CO}$, como es la utilización de grupos electrógenos hogareños (Figuras 1, 2 y 3) para abastecernos de energía eléctrica en forma transitoria. Por tratarse de un uso para la emergencia ante esta situación, son colocados en forma inapropiada y se genera combustión en el ambiente. Por funcionar con nafta o diésel, los generadores emanan $\mathrm{CO}$, por eso su ubicación debe ser en espacios ventilados, alejados de rejillas de respiración, ventanas, puertas o patios interiores. Es importante colocarlos de modo que los vientos alejen los gases de la casa.

También llamado "el gran simulador", el CO se forma durante la combustión incompleta de cualquier compuesto que contiene carbono.

FIgURA 1. Grupo electrógeno de uso domiciliario, sin carteles de advertencia

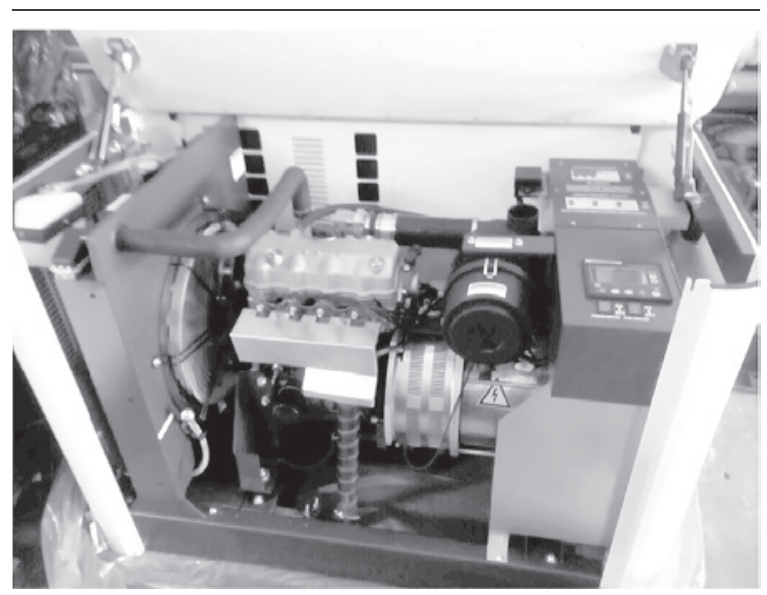

Debido a que es un gas inodoro, menos denso que el aire, incoloro e insípido, es muy difícil de detectar en el medio ambiente, incluso cuando está presente en altas concentraciones, y es una causa importante de morbilidad y mortalidad por intoxicación. El problema más grave con el envenenamiento con $\mathrm{CO}$ suele ser la morbilidad asociada a los sobrevivientes, incluso luego de recibir el tratamiento en la exposición aguda. La complicación neurológica más seria es la aparición tardía y persistente de secuelas neurocognitivas, ${ }^{3}$ que se puede producir en los pacientes que sufren intoxicaciones graves.

Luego de ingresar por las vías respiratorias, atraviesa los alvéolos, pasa a la sangre, se distribuye por todos los tejidos y causa hipoxia tisular e inhibición de la respiración celular. ${ }^{4}$ Al ligarse a la hemoglobina con una afinidad, aproximadamente, 250 veces mayor que la de oxígeno, perjudica su entrega y produce

FIGURA 2. Grupo electrógeno de uso domiciliario

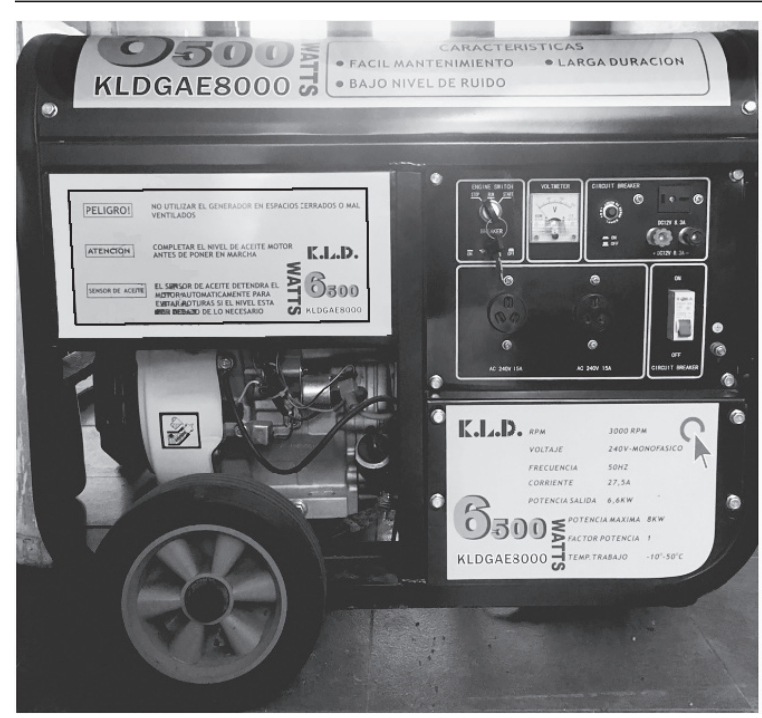

Figura 3. Ampliación del cartel de advertencia de no uso en espacios cerrados

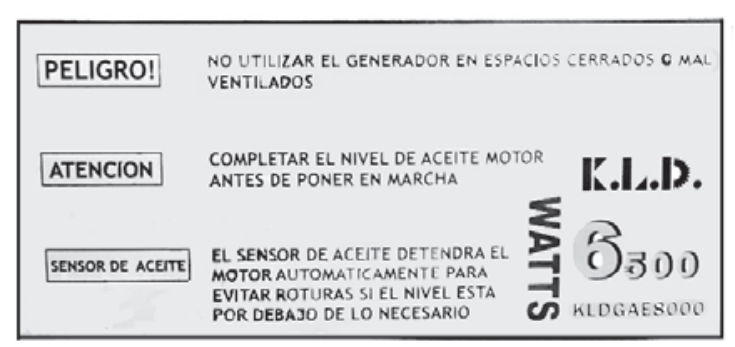


hipoxia celular e isquemia. ${ }^{5}$ Se agrega a esto su mayor afinidad por la mioglobina (60 veces mayor). Además de los mencionados, existen múltiples mecanismos que contribuyen a su toxicidad, como la unión a la citocromo oxidasa, guanilato ciclasa, peroxidación lipídica y la afectación de la adherencia leucocitaria. ${ }^{6} \mathrm{Si}$ bien la toxicidad es sistémica, la hipoxia tisular grave afecta, principalmente, al cerebro y al corazón. Recordemos que atraviesa también la placenta y posee gran afinidad por la hemoglobina fetal, lo cual puede perjudicar un embarazo.

Como fuentes de producción de $\mathrm{CO}$, cualquier proceso de combustión incompleta de productos carbonados puede generarlo. En nuestro medio, los elementos utilizados para producir calor son los más frecuentes. Se destacan los braseros, estufas, cocinas, salamandras, calderas, que, en todos los casos, hay una incorrecta salida al exterior o ambientes mal ventilados, $y$, en los últimos años, se suman los grupos electrógenos. En América del Norte, las fuentes más comunes son los incendios domésticos, hornos caseros, estufas, calentadores de agua y gases de los vehículos. ${ }^{5}$ Existen otras fuentes de producción exógena (motores, caños de escape, consumo de cigarrillos) y de producción endógena (embarazo, anemias, etcétera). ${ }^{6}$ Otra forma menos frecuente de intoxicación es el cloruro de metileno, utilizado como removedor de pintura o desengrasante. Se absorbe a través de la inhalación, ingestión o absorción cutánea y se metaboliza en el hígado a CO. ${ }^{5}$

Con respecto al diagnóstico, será fundamental la anamnesis minuciosa de los acontecimientos. Como en toda situación en la que existan múltiples involucrados, debe orientarse en la búsqueda de signos y síntomas que muestren conjuntamente los presentes, y se puede detectar, muchas veces, el caso índice. El haber compartido un ambiente, el cuadro clínico de presentación grupal, la exposición a una fuente de combustión y la presencia de climas fríos, en la mayoría de los casos, son la clave para el diagnóstico.

En nuestro caso, se trataba de una fuente de combustión instalada no con el fin de calefaccionar, sino de abastecimiento de luz. En el inicio, fue interpretado por los asistentes como un cuadro viral generalizado, que, dadas las características tan abruptas de aparición, no era compatible hasta que se llegó a la fuente de intoxicación.

Por tratarse de un evento masivo, frecuentemente, es asumido en forma errónea como una intoxicación alimentaria grupal. Los primeros síntomas en aparecer son cefalea, vómitos e hipotonía de los miembros inferiores, ${ }^{6}$ que, al comprometer también al resto del grupo de individuos, genera un alerta. El grado de intoxicación dependerá de la concentración de $\mathrm{CO}$ en el aire inspirado, el tiempo de exposición, el volumen minuto respiratorio (varía con la edad, la actividad y se triplica si hay trabajo energético), la concentración de hemoglobina en sangre (mayor gravedad en pacientes con anemia) y el mayor índice metabólico (mayores síntomas en niños). ${ }^{7}$

El sistema nervioso central es el órgano más sensible a la intoxicación por CO aguda. Los pacientes sanos pueden manifestar cefalea, mareos, ataxia con niveles de $\mathrm{COHb}$ de $15 \%$ $20 \%$; con niveles más altos o exposiciones más largas, puede causar síncope, convulsiones o coma. ${ }^{3}$ De persistir la exposición, aparece deterioro del sensorio progresivo, convulsiones y coma. En el sistema cardiovascular, observamos, generalmente, hipotensión arterial (puede existir lo contrario), arritmias, angor, infarto agudo de miocardio, y se puede exacerbar el riesgo de lesión en el paciente con patología de base. El compromiso neurológico y cardiológico son la prioridad, aunque debe tenerse en cuenta que, por tratarse de un gas con afectación sistémica, repercute en otros órganos y provoca rabdomiólisis, falla renal, dificultad respiratoria variable, entre otros. El diagnóstico específico lo obtendremos a través del dosaje de $\mathrm{COHb}$. Es importante destacar el método de extracción y la latencia existente (el momento de exposición al tóxico hasta la extracción de la muestra), lo que permite tomar conductas oportunas y evitar gastos injustificados. Deben extraerse 3-5 $\mathrm{ml}$ de sangre venosa o arterial en una jeringa heparinizada, con obturador y sin burbujas de aire (valor de referencia de $\mathrm{COHb}$ : 0,5\%$1,5 \%)$. El oxígeno ambiental contribuye en la disolución de la $\mathrm{COHb}$, lo cual debe considerarse para una intervención adecuada. La vida media de eliminación depende de la concentración en el ambiente: a oxígeno ambiental, es de 5-6 h; a oxígeno al 100\%, 40-90 minutos; y a oxígeno hiperbárico (2,5 atmósferas), menos de 20 minutos. $^{7}$

Para continuar con la evaluación cardiológica, se solicitó electrocardiograma (ECG) (desde cambios de tipo isquémico -infradesnivel del ST-, arritmias, a, incluso, infarto de miocardio), creatina fosfocinasa (CPK), creatina fosfocinasa miocárdica (CPK-MB) y troponina según cada 
caso en particular. Las neuroimágenes, como la resonancia magnética nuclear, se solicitan en el caso de compromiso neurológico grave a fin de descartar una complicación aguda o en el seguimiento de los pacientes que presenten síndrome neuropsiquiátrico tardío (deterioro neurológico y/o psiquiátrico que aparece entre los 3 días y los 3 meses de exposición). Está causado por la lesión celular y las áreas de desmielinización, que se producen por efecto del tóxico. . $^{8-10}$

Ante una situación en la que exista una intoxicación masiva, debe retirarse a los pacientes del ambiente contaminado lo más precozmente posible y solicitar un apoyo vital en forma inmediata. Esta exposición debe diferenciarse de la inhalación de humo que sucede en los incendios, en los que pueden coexistir más de 25 compuestos diferentes. Puede tratarse de material particulado, por ejemplo, el hollín, gases irritantes de la vía aérea, gases no irritantes (como el CO y el cianuro), como producto de la combustión de plásticos, y los mecanismos lesivos son la asfixia, el daño térmico y la irritación pulmonar. ${ }^{11}$ Se deben aplicar, en todos los casos, medidas de soporte vital básico, administrar oxígeno (máscara con reservorio o asistencia respiratoria mecánica) de manera precoz y continua lo más cercano posible al $100 \%$ hasta que desaparezca la sintomatología (Figura 4). ${ }^{1} \mathrm{La}$

FIGURA 4. Intoxicación con monóxido de carbono: algoritmo terapéutico

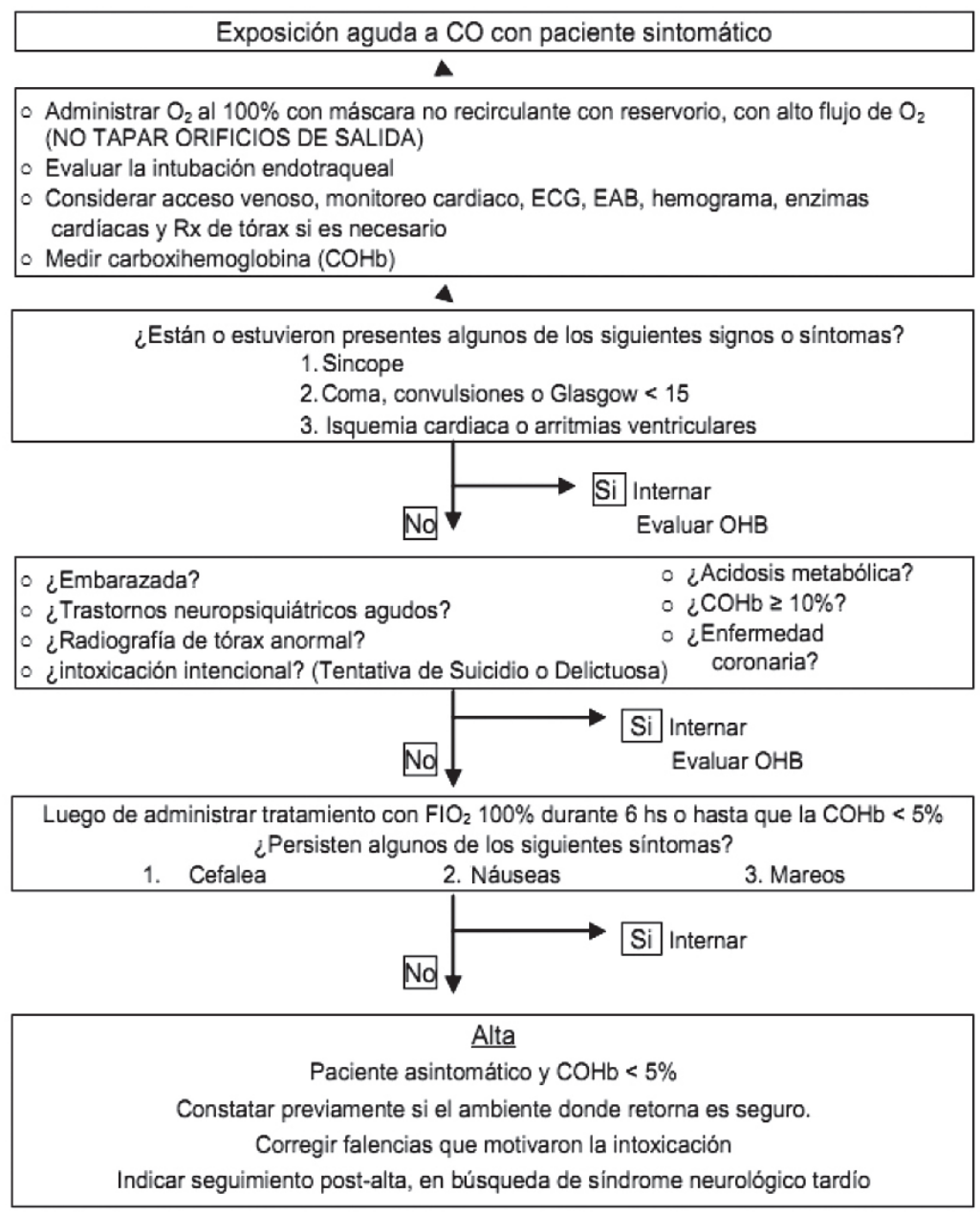

Fuente: García SI. ${ }^{1}$ Guía de prevención, diagnóstico, tratamiento y vigilancia epidemiológica de las intoxicaciones por monóxido de carbono. $2^{\text {a }}$ ed. Buenos Aires: Ministerio de Salud de la Nación. Página 32.

CO: monóxido de carbono.

OHB: oxígeno hiperbárico. 
cámara hiperbárica disminuye la vida media del $\mathrm{CO}$ a 20 minutos, lo que mejora la sintomatología aguda y previene la aparición de secuelas. Weaver y cols. evidencian diferencias significativas en la evolución de los pacientes tratados con oxígeno hiperbárico a corto y a largo plazo, así como en la incidencia de síndrome neurológico tardío, $8,12,13$ aunque no son concluyentes. Debe indicarse en todo paciente con signo neurológico focal, pérdida de conciencia, $\mathrm{COHb}>30 \%$, embarazadas sintomáticas o con valores de $\mathrm{COHb}$ $>20 \%$ preferentemente dentro de las 6 horas de la intoxicación. Los pediatras debemos estar alerta ante cuadros que incluyan los síntomas mencionados, sobre todo en invierno, si existen varias personas afectadas simultáneamente y si los pacientes mejoran al salir a la calle. ${ }^{14}$ Recordemos que, muchas veces, el disponer de un grupo electrógeno para abastecernos de luz es una opción válida siempre y cuando el uso en el lugar sea el adecuado y/o autorizado, con las instrucciones de uso, normas de fabricación y advertencias correspondientes, lo cual no siempre se cumple. Como todo artefacto que genere combustión, debe ser utilizado con conocimiento y prudencia.

\section{CONCLUSIÓN}

Todos podemos ser víctimas de la intoxicación con CO en el hogar, el trabajo, la escuela, en un sitio de recreación, en un centro de salud, en cualquier lugar cerrado que tenga una fuente de combustión. La intoxicación con CO es prevenible $y$, si es prevenible, es evitable. Para ello, existen herramientas: el conocimiento de su existencia, el cumplimiento de la legislación, los programas de prevención efectivos, la notificación y vigilancia epidemiológica, entre otras cosas. Aún queda pendiente fortalecer nuestros programas de acción en emergencias que involucran a múltiples víctimas. En este caso, la evolución de los pacientes fue favorable, gracias al trabajo a conciencia de todo el personal comprometido, lo cual nos alienta a seguir trabajando.

\section{REFERENCIAS}

1. García SI. Guía de prevención, diagnóstico, tratamiento y vigilancia epidemiológica de las intoxicaciones por monóxido de carbono. 2. ${ }^{a}$ ed. Buenos Aires: Ministerio de Salud de la Nación. Programa Nacional de Prevención y Control de las Intoxicaciones, 2016:6-7. [Acceso: 7 de octubre de 2016]. Disponible en: http://www.msal.gob. ar/images/stories/bes/graficos/0000000530cnt-2016_ Guia_Monoxido.pdf.

2. Mintegi Raso S, Azkunaga Santibañez B. Epidemiología de los intoxicados en pediatría. En: Mintiegi S, Grupo de Trabajo de Intoxicaciones de la Sociedad Española de Urgencias de Pediatría. Manual de intoxicacionesen Pediatría. 2. ${ }^{a}$ ed. Barcelona: Ergon; 2008.Págs.3-8.

3. Tomaszewski C. Carbon monoxide. En Hoffman R, Howland M, Lewin N, Nelson L, etal. Goldfrank's Toxicologic Emergencies. 10 ${ }^{\text {th }}$ ed. New York: Mc Graw Hill; 2015. Págs.2681-5.

4. Leikin J, Paloucek F. Carbon monoxide. En Poisoning $\mathcal{E}$ Toxicology Handbook. 4. ${ }^{\text {a }}$ ed. New York: Press; 2007.Págs. 768-9.

5. Carbon monoxide. In Klasco RK, ed.POISINDEX® System . Greenwood Village, CO: Truven Health Analytics, vol.169, expires 9/2016.

6. Talamoni M, Crapanzano G, Greco V. Hipoxias de origen tóxico. Monóxido de carbono. En: Guía de diagnóstico y tratamiento en Toxicología. 2. ${ }^{a}$ ed. Buenos Aires: Eudeba; 2014.Págs.95-8.

7. Curci O. Hipoxias tóxicas. En Toxicología. 2. ${ }^{a}$ ed. Buenos Aires: La Prensa Médica; 2005.Págs.40-4.

8. NetCastel A,Marruecos-Sant L. Intoxicación por monóxido de carbono. Daño celular y síndrome neurológico tardío. En: Intoxicaciones agudas graves. Barcelona: Ars Médica; 2006.Págs.116-7.

9. Gorman D, Drewry A, Huang YL, Sames C. The clinical toxicology of carbonmonoxide. Toxicology 2003;187(1):25-38.

10. Thom SR, Fisher D, Xu YA, Notarfrancesco K, et al. Adaptative responses and apoptosis in endothelial cells exposed to carbon monoxide. Proc Natl Acad Sci USA 2000;97(3):1305-10.

11. Ling L, Clark R, Erickson T, Trestrail III J. Inhalación de humo. Monóxido de carbono. En Secretos de la Toxicología. México: McGraw-Hill/Interamericana; 2002.Págs.233-7.

12. Thorns SR. Hyperbaric-oxygen therapy for acute carbon monoxide poisoning. N Engl J Med 2002;347(14):1105-6.

13. Weaver LK, Hopkins RO, Chan KJ, Churchill S, et al. Hyperbaric oxygen for acute carbon monoxide poisoning. N Engl JMed 2002;347(14):1057-67.

14. De la Torre Espí M, Molina Cabañero JC. Intoxicaciones por monóxido de carbono. En MintiegiS, Grupo de Trabajo de Intoxicaciones de la Sociedad Española de Urgencias de Pediatría. Manual de intoxicaciones en Pediatría. 2. ${ }^{a}$ ed. Barcelona: Ergon; 2008.Págs.259-68.

15. Albiano N, Villaamil Lepori E. Monóxido de carbono. En Toxicología laboral: criterios para el monitoreo de la salud de los trabajadores expuestos a sustancias químicas peligrosas. 4 . $^{\mathrm{a}} \mathrm{ed}$. Buenos Aires: Superintendencia de Riesgos del Trabajo; 2015.Págs.334-5. 